\title{
Tooth Autotransplantation with Autogenous Tooth-Bone Graft: A Case Report
}

\section{Young-Kyun Kim', Yong-Hoon $\mathrm{Choi}^{2}$}

1. Department of Oral and Maxillofacial Surgery, Section of Dentistry, Seoul National University Bundang Hospital, Seongnam, Korea

2. Department of Conservative Dentistry, Section of Dentistry, Seoul National University Bundang Hospital, Seongnam, Korea

\section{Corresponding Author}

\section{Yong-Hoon Choi, DDS, MSD}

Department of Conservative Dentistry, Section of Dentistry, Seoul National University Bundang Hospital, 300 Gumi-dong, Bungdang-gu, Seongnam 463-707, Korea

TEL : +82-31-787-7543 FAX : +83-31-787-4068 E-mail : yhchoi@snubh.org

Received for publication September 7, 2011; Returned after revision October 28, 2011; Accepted for publication November 5, 2011

\section{- Abstract}

The extracted right mandibular third molar of a 37-year-old man was transplanted into the first molar area, and a bone graft procedure using autogenous tooth-bone graft material was performed for the space between the root and the alveolar socket. Reattachment was achieved after 10 months. Therefore, autogenous toothbone graft material is considered reasonable for bone induction and healing in the autotransplantation of teeth.

\section{- Key word : Tooth-bone graft, Bone graft, Autotransplantation of teeth}

- J Kor Dent Sci. 2011; 4(2) : 79 - 84

(a) This is an open access article distributed under the terms of the Creative Commons Attribution Non-Commercial License (http:// creativecommons.org/licenses/by-nc/3.0) which permits unrestricted non-commercial use, distribution, and reproduction in any medium, provided the original work is properly cited. 


\section{Introduction}

The autotransplantation of teeth is a surgical procedure wherein a tooth (e.g., the third molar) is extracted and transplanted to a different surgically formed location or another part of an extraction socket within the arch to restore the hopeless teeth or edentulous area caused by the congenital absence of teeth, extensive caries, periodontal disease, trauma, or endodontic failure. The health of the periodontal ligament of the donor tooth and the fit with the recipient's relevant bone site are very important factors for the autotransplantation of teeth. If the extraction socket size is large, or there is insufficient bone due to periodontal disease, an additional bone graft procedure using autogenous bone or other bone graft materials is required. Among the various bone graft materials, autogenous bone is known as the best material for bone regeneration and engraftment of transplanted teeth. Note, however, that it has demerits such as bone graft donor site complication.

The development of bone graft material using extracted human teeth has been performed through laboratory experiments since 1993, and biocompatible bone conductive materials have been found ${ }^{1-4)}$. Based on these studies, autogenous tooth-bone graft material was developed by processing the extracted teeth from patients through stateof-the-art processes, enabling the development of bone graft surgery for the same patients. Autogenous tooth-bone graft material (AutoBT, Korean Tooth Bank, Seoul, Korea) resulted in healing after transplantation through bone induction and conduction, and it has proven to be highly biocompatible $\mathrm{e}^{5,6)}$.

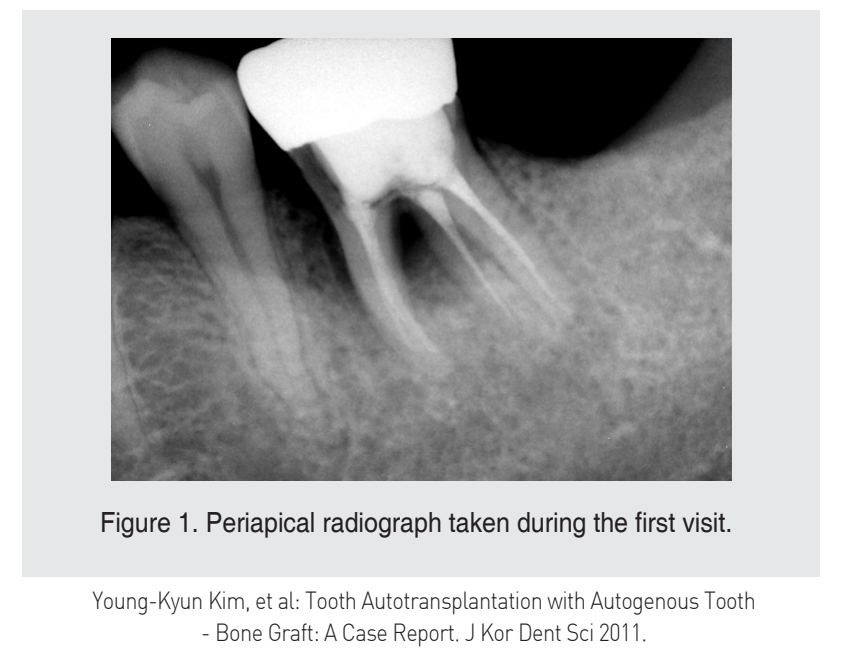

This case report describes a patient showing good stabilization and excellent periodontal regenerative healing after autogenous tooth transplantation using a bone graft technique with autogenous tooth-bone graft material.

\section{Case Report}

On June 5, 2009, a 37-year-old man was referred to Seoul National University Bundang Hospital for treatment of the left mandibular first molar that showed pus discharge from the buccal gingiva (Fig. 1). On July 7, 2009, under local anesthesia, the left mandibular second and third molars were extracted, and the patient was referred to the Department of Conservative Dentistry for the treatment of the first

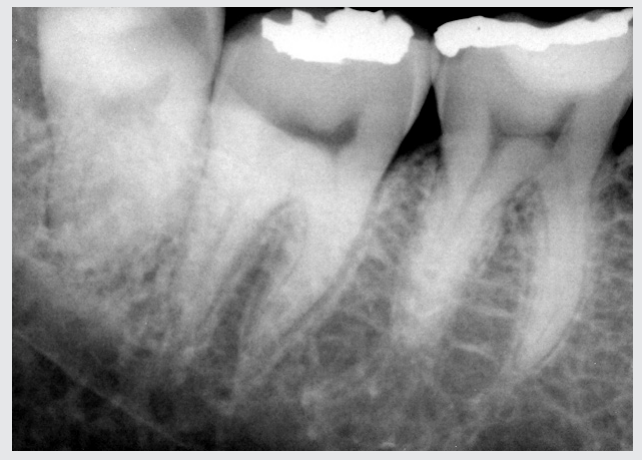

Figure 2. A decision to perform autotransplantation using the mandibular posterior teeth was made. The third molar to the left mandibular first molar area is shown.

Young-Kyun Kim, et al: Tooth Autotransplantation with Autogenous Tooth - Bone Graft: A Case Report. J Kor Dent Sci 2011.

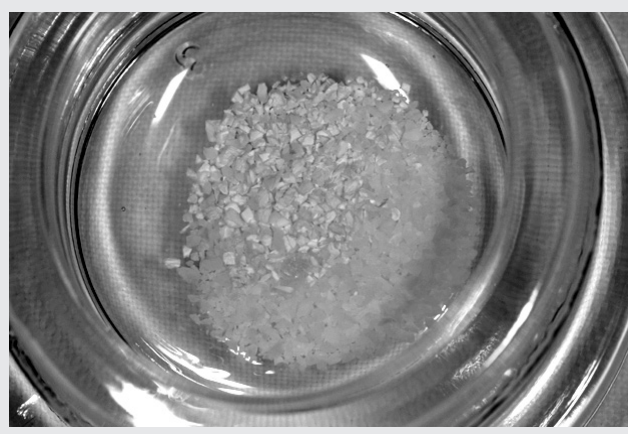

Figure 3. Autogenous tooth-bone powder prepared from the extracted first molar.

Young-Kyun Kim, et al: Tooth Autotransplantation with Autogenous Tooth - Bone Graft: A Case Report. J Kor Dent Sci 2011 
molar. In the radiography, a vertical root fracture was observed; thus, the first molar could not be saved. As such, autotransplantation was attempted using autogenous toothbone graft material, with the right mandibular third molar selected as donor tooth (Fig. 2). On April 23, 2010, the left mandibular first molar tooth was extracted and sent to the laboratory (AutoBT, Korean Tooth Bank, Seoul, Korea) for autogenous tooth-bone graft material preparation (Fig. 3). Transplantation surgery was delayed for 1 month to allow the soft connective tissue to cover the extraction socket. On May 25, 2010, autotransplantation was carried out, and autogenous tooth-bone grafting was performed in the bony defect around the transplanted tooth and extraction socket (Figs. 4 8). The extra-alveolar time was 2 min and $23 \mathrm{~s}$. The transplanted tooth was splinted for 3 weeks using a conventional resin-wire splint for fixation (Fig. 9). On July 6,2010 , one-visit endodontic treatment of the tooth was

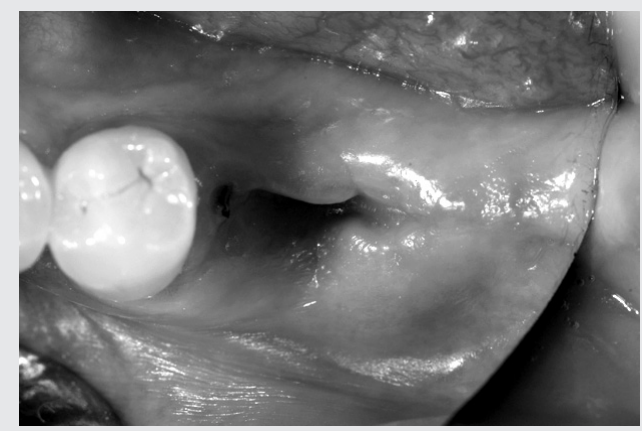

Figure 4. One month after extraction.

Young-Kyun Kim, et al: Tooth Autotransplantation with Autogenous Tooth Bone Graft: A Case Report. J Kor Dent Sci 2011.

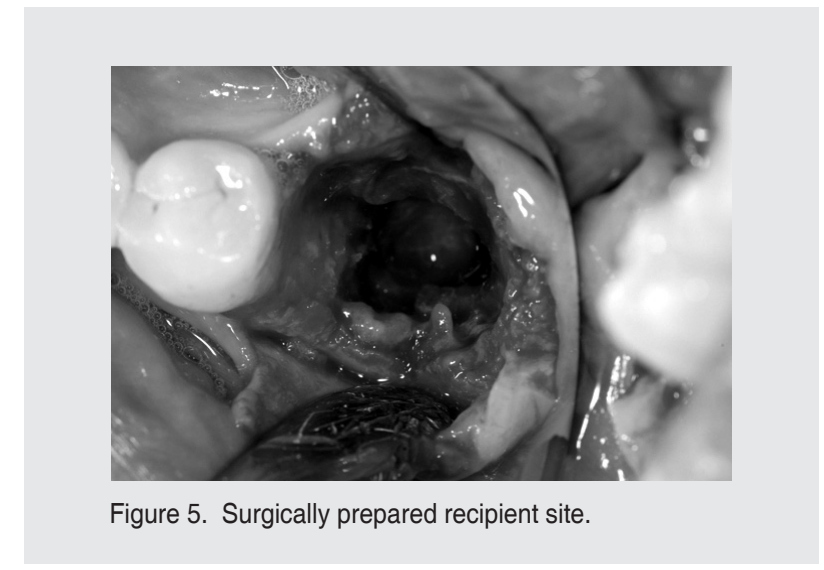

Figure 5. Surgically prepared recipient site.

Young-Kyun Kim, et al: Tooth Autotransplantation with Autogenous Tooth

- Bone Graft: A Case Report. J Kor Dent Sci 2011. performed. The transplanted tooth healed fairly well, and tooth mobility decreased. The resin core was prepared using composite resin, and occlusal contact was established in the

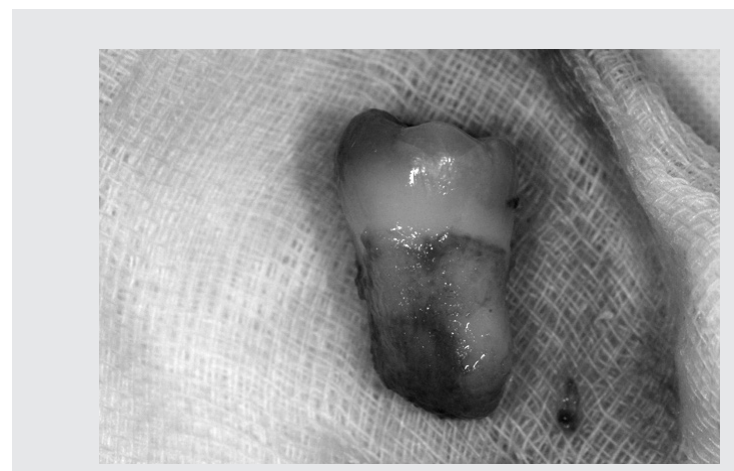

Figure 6. Extracted right mandibular third molar.

Young-Kyun Kim, et al: Tooth Autotransplantation with Autogenous Tooth - Bone Graft: A Case Report. J Kor Dent Sci 2011.

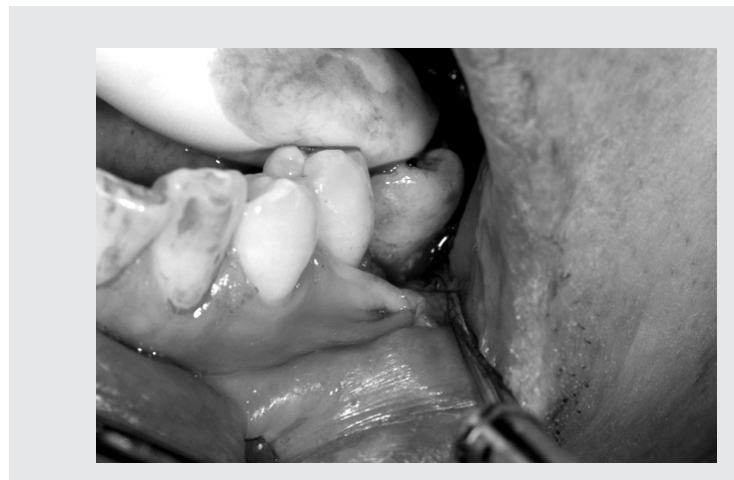

Figure 7. Placement of the third molar in the recipient site.

Young-Kyun Kim, et al: Tooth Autotransplantation with Autogenous Tooth - Bone Graft: A Case Report. J Kor Dent Sci 2011.

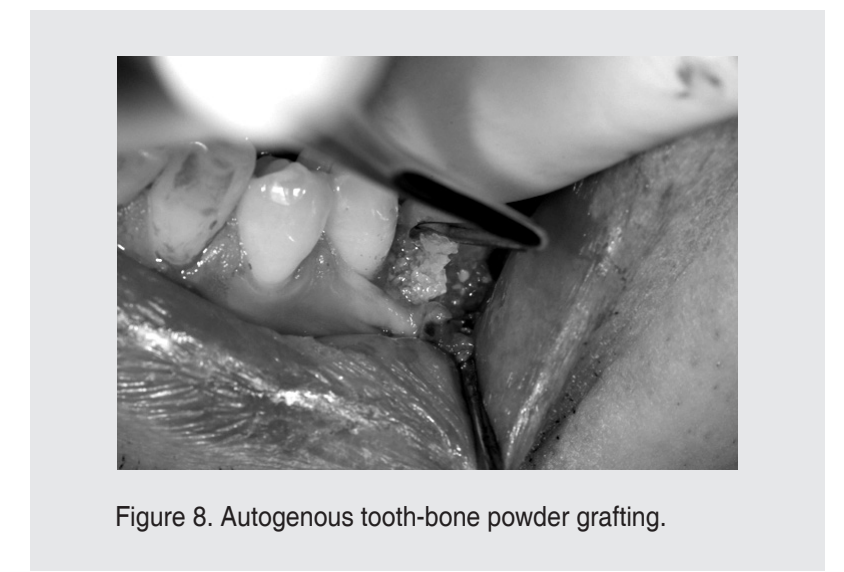

Figure 8. Autogenous tooth-bone powder grafting.

Young-Kyun Kim, et al: Tooth Autotransplantation with Autogenous Tooth

- Bone Graft: A Case Report. J Kor Dent Sci 2011 


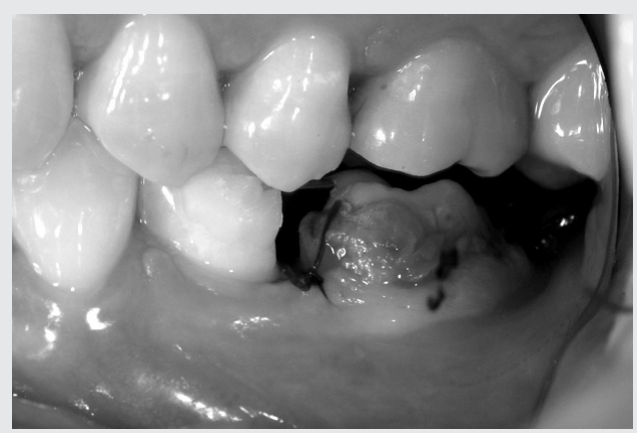

Figure 9. After surgery, the transplanted tooth was splinted to \#35 using conventional resin-wire splint.

Young-Kyun Kim, et al: Tooth Autotransplantation with Autogenous Tooth - Bone Graft: A Case Report. J Kor Dent Sci 2011.

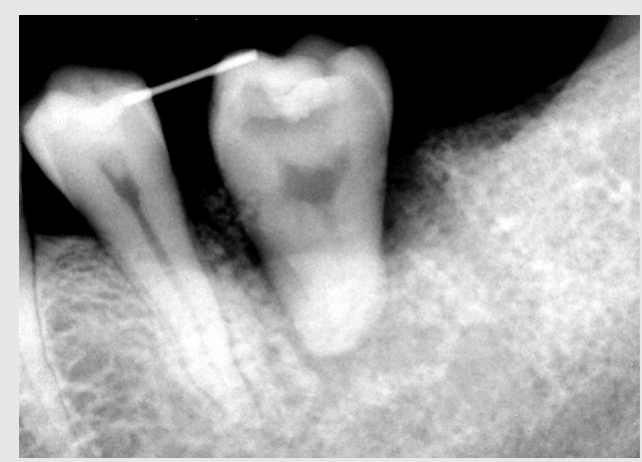

Figure 10. Postoperative periapical radiograph.

Young-Kyun Kim, et al: Tooth Autotransplantation with Autogenous Tooth - Bone Graft: A Case Report. J Kor Dent Sci 2011

central fossa opposing the palatal root tip of the maxillary first molar (Figs. 9 12). A periapical radiograph taken 10 months after surgery showed complete regeneration of the periodontal ligament, normal physiological mobility without ankylosis, and pathological root resorption (Fig. 13). The patient could masticate using the transplanted tooth; he reported no discomfort or pain and wanted the final restoration to be performed at a private dental clinic.

\section{Discussion}

During autotransplantation, a large bony defect usually occurs due to the difference between the size of the recipient site and that of the donor tooth or owing to periodontal disease. In this case, autogenous bone can be obtained from the bony septum or from the surroundings of the recipient site using osteotomy. Allogenic xenograft or synthetic bone

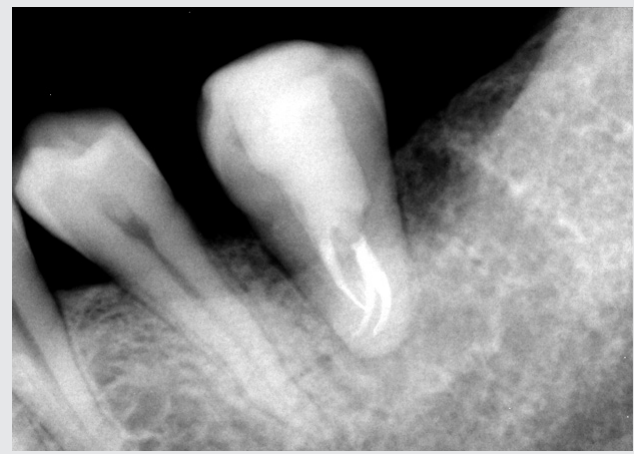

Figure 11. Periapical radiograph taken 3 months after surgery.

Young-Kyun Kim, et al: Tooth Autotransplantation with Autogenous Tooth - Bone Graft: A Case Report. J Kor Dent Sci 2011

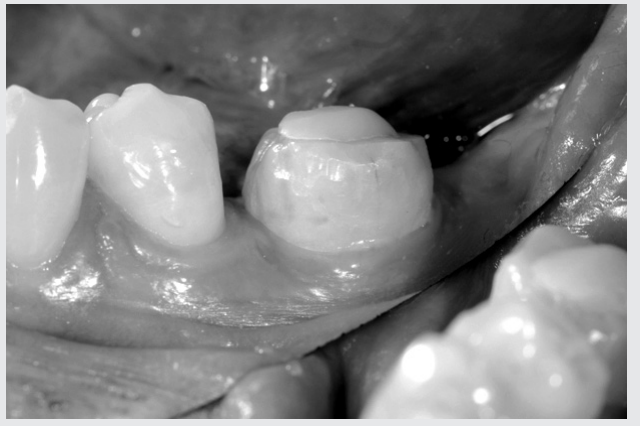

Figure 12. Ten months after surgery, composite resin was built up to ensure occlusal contact with the opposing tooth.

Young-Kyun Kim, et al: Tooth Autotransplantation with Autogenous Tooth - Bone Graft: A Case Report. J Kor Dent Sci 2011

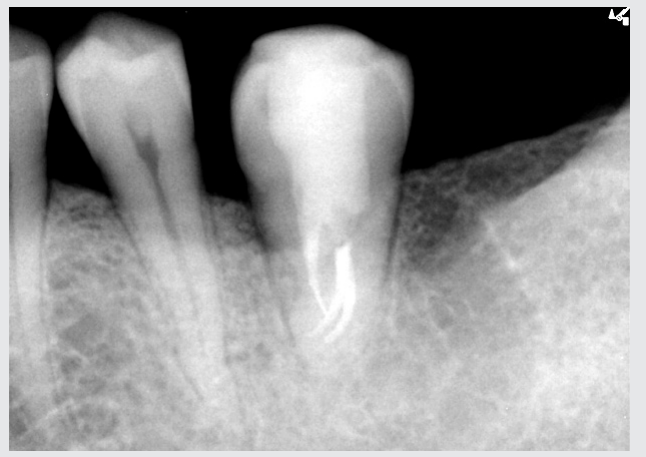

Figure 13. Periapical radiograph taken 10 months after surgery.

Young-Kyun Kim, et al: Tooth Autotransplantation with Autogenous Tooth - Bone Graft: A Case Report. J Kor Dent Sci 2011.

graft materials can also be used ${ }^{7}$.

If the recipient bone is insufficient, or there is mesio-distal 
and bucco-lingual discrepancy, the donor tooth can be rotated $90^{\circ}$ or $180^{\circ}$. If the floor of the maxillary sinus is low, leaving insufficient room for the donor tooth, the septal bone can be raised to the level of the maxillary sinuses using an osteotome to make room for the donor tooth ${ }^{7,8)}$.

In the present case, a month after the left mandibular first molar extraction, autotransplantation was performed to ensure sufficient formation of the attached gingiva over the extraction socket. Although the soft tissue healed well, incomplete bone healing of the extraction socket was observed. The bony defect enabled the easy placement of the donor tooth, but the large space between the donor tooth and the extraction socket impaired the regeneration of bone and periodontal tissue. Autogenous tooth-bone graft material was used to restore the defect and stabilize the transplanted tooth.

The transplanted teeth must be fixed with resin-wire or fiber splint, and the occlusal interference must be removed. If the root is long, and the initial stability is good, tying of the over-crown suture is sufficient, and transplanted teeth are fixed for 2 3 weeks. Long-term rigid fixation negatively affects the healing of the periodontal ligament cells, whereas non-rigid fixation for $7 \sim 10$ days may promote the healing and activity of these cells ${ }^{8,9)}$. Note, however, that Tsukiboshi performed non-rigid fixation for 2 weeks $\sim 2$ months depending on the decrease in tooth mobility ${ }^{10)}$. In the present case, fixation to the adjacent teeth using resinwire splint was performed for 3 weeks. Endodontic treatment may be administered for the transplanted tooth preoperatively, intraoperatively, or postoperatively. With regard to the endodontic treatment during teeth transplantation, some researchers recommended that endodontic treatment be performed prior to the extraction of the donor tooth, since it is very important to shorten the extra-oral time and trauma of the periodontal membrane. If intraoperative endodontic treatment is performed, the extracted donor tooth should be wrapped with saline-soaked gauze to reduce damage to the periodontal ligament. Postoperative endodontic treatment should be performed within 1 2 weeks of surgery. Certain studies have reported that inflammatory root resorption can occur if endodontic treatment is not initiated within 2 weeks ${ }^{7,811-13)}$. In the present case, we performed endodontic treatment 12 days after surgery. Access and visibility issues impeded the execution of preoperative endodontic treatment for the donor tooth.

After the autotransplantation of the teeth, periodontal ligament healing was classified as reattachment or new atta- chment. Reattachment refers to the reunion between the root surface periodontal ligament and bony periodontal ligament separated by artificial incision or trauma. Intentional replantation results in the repositioning of the extracted teeth to the original position in a short period of time. In autotransplantation, however, the healing of the periodontal ligament differs from that in replantation, which may be due to the absence of periodontal ligament in the recipient site when autotransplantation is performed ${ }^{8,14)}$. Andreasen determined the prognosis of transplantation and replantation by assessing the attachment of the periodontal membrane to the root surface. The periodontal membrane present in the alveolar socket has not been reported to induce new attachment or reattachment ${ }^{15,16)}$. Therefore, in teeth replantation and autotransplantation surgery, the protection of the root-surface periodontal ligament is vital. New attachment refers to the reunion between the connective tissue and the root surface exposed to a disease. In several experiments, when teeth with insufficient periodontal ligament were transplanted, healing via new attachment was observed ${ }^{8,14)}$.

The success of autogenous tooth transplantation can be judged based on the clinical, radiographic, and histologic viewpoints $^{8,17,18)}$. The success criteria from the clinical viewpoint are as follows: (1) no pathological tooth mobility, (2) normal percussion sound, (3) no loss of attached gingiva, (periodontal pocket), (4) no gingival inflammation, (5) no abnormal symptoms, and (6) normal masticatory function. The radiographic success criteria are as follows: (1) normal periodontal ligament space around the transplanted teeth, (2) no progressive root absorption, and (3) presence of lamina dura. The histological success criteria require the appearance of periodontal membrane fibers arranged perpendicularly to the root surface in tissue sections. Note, however, that histological examinations are usually impossible in clinical situations. In this study, tooth mobility and periodontal pocket were not observed. In the radiography, no root absorption was noted, but a definite periodontal membrane space including lamina dura was found. Thus, the success criteria were met, and final prosthetic treatment could be performed.

Many authors have reported the success of autotransplantation of teeth. Tsukiboshi reported 250 cases over 6 years and noted a $90 \%$ survival rate and $82 \%$ success rate ${ }^{11)}$. Lundberg reported a $94 \%$ success rate for patients with incompletely formed root and an $84 \%$ success rate for patients with completely formed root, indicating that the 
autotransplantation of teeth with an incompletely formed root showed higher success rate ${ }^{17)}$. Majare also reported a high success rate in teeth with complete root formation ${ }^{19}$. In the present study, we showed that a 37-year-old man with a third molar transplantation successfully had complete root formation. Furthermore, through the evaluation of clinical and radiographic findings, healing by reattachment could be estimated.

For successful autotransplantation, damage due to extra-oral time on the donor tooth root should be minimized, and primary soft tissue close - especially in the cervical areamust be achieved. In our case, the extra-alveolar time was less than $3 \mathrm{~min}$, although the cervical area was accurately approximated without infection. If the donor tooth does not fit well within the recipient site, however, the gap between the donor tooth and alveolar socket can be filled using autogenous bone or other bone graft materials ${ }^{19)}$. Autogenous bone is considered an ideal material for hard tissue defects because it promotes osteogenesis, osteoinduction, and osteoconduction. A recently developed autogenous tooth-bone graft material containing organic and inorganic mineral components was prepared from autogenous grafting material, reportedly possessing excellent bone healing properties of osteoinduction and osteoconduction ${ }^{6}$. In our case, the initial stability could have increased with the use of this autogenous tooth-bone graft material. Additionally, we think successful healing by reattachment can be facilitated by the osteoinduction and osteoconduction properties of autogenous tooth-bone graft material.

In conclusion, we advocate the use of autogenous toothbone graft material for the bone graft procedure, which may be required in the autotransplantation of teeth.

\section{References}

1. Kim YK, Yeo HH, Ryu CH, Lee HB, Byun UR, Cho JO. An experimental study on the tissue reaction of toothash implanted in mandible body of the mature dog. J Korean Assoc Maxillofac Plast Reconstr Surg. 1993; 15: 129-36.

2. Kim YK, Yeo HH, Yang IS, Seo JH, Cho JO. Implantation of toothash combined with plaster of Paris: experimental study. J Korean Assoc Maxillofac Plast Reconstr Surg. 1994; 16: 122-9.

3. Kim SG, Chung CH, Kim YK, Park JC, Lim SC. Use of particulate dentin-plaster of Paris combination with/without platelet-rich plasma in the treatment of bone defects around implants. Int J Oral Maxillofac Implants. 2002; 17: 86-94.

4. Kim SG, Kim HK, Lim SC. Combined implantation of particulate dentine, plaster of Paris, and a bone xenograft (Bio-Oss) for bone regeneration in rats. J Craniomaxillofac Surg. 2001; 29: 282-8.

5. Kim YK, Lee HJ, Kim SG, Um IW, Lim SC, Kim SY. Analysis of inorganic component and SEM analysis of autogenous teeth bone graft material and histomorphometric analysis after graft. J Korean Acad Implant Dent. 2009; 28: 1-9.

6. Kim YK, Kim SG, Byeon JH, Lee HJ, Um IU, Lim SC, Kim SY. Development of a novel bone grafting material using autogenous teeth. Oral Surg Oral Med Oral Pathol Oral Radiol Endod. 2010; 109: 496503.

7. Bae JH, Choi YH, Cho BH, Kim YK, Kim SG. Autotransplantation of teeth with complete root formation: a case series. J Endod. 2010; 36: $1422-6$

8. Kim YK, Bae JH, Choi YH, Kim SG, Um IW: A variety of Grafting Procedures Using Teeth. 1st ed. Seoul: Daehan Narae Pub. Co.; 2011. p. $26-52$
9. Chamberlin JH, Goerig AC. Rationale for treatment and management of avulsed teeth. J Am Dent Assoc. 1980; 101: 471-5.

10. Tsukiboshi M: Autotransplantation of Teeth. 1st ed. Chicago: Quintes sence; 2001. p. 10-14, 97, 152-67.

11. Tsukiboshi M. Autotransplantation of teeth: requirements for predictable success. Dent Traumatol. 2002; 18: 157-80.

12. Fong CC. Transplantation of the third molar. Oral Surg Oral Med Oral Pathol. 1953; 6: 917-26.

13. Pogrel MA. Evaluation of over 400 autogenous tooth transplants. J Oral Maxillofac Surg. 1987; 45: 205-11

14. Lindskog S, Blomlöf L. Influence of osmolality and composition of some storage media on human periodontal ligament cells. Acta Odontol Scand. 1982; 40: 435-41.

15. Andreasen JO. Effect of extra-alveolar period and storage media upon periodontal and pulpal healing after replantation of mature permanent incisors in monkeys. Int J Oral Surg. 1981; 10: 43-53.

16. Andreasen JO. Periodontal healing after replantation and autotransplantation of incisors in monkeys. Int J Oral Surg. 1981; 10: 54-61.

17. Lundberg T, Isaksson S. A clinical follow-up study of 278 autotransplanted teeth. Br J Oral Maxillofac Surg. 1996; 34: 181-5.

18. Schwartz-Arad D, Herzberg R, Levin L. Evaluation of long-term implant success. J Periodontol. 2005; 76: 1623-8.

19. Mejàre B, Wannfors K, Jansson L. A prospective study on transplantation of third molars with complete root formation. Oral Surg Oral Med Oral Pathol Oral Radiol Endod. 2004; 97: 231-8. 